\title{
THE EFFECT OF Xe ION AND NEUTRON IRRADIATION ON THE PROPERTIES OF SiC AND SiC(N) FILMS PREPARED BY PECVD TECHNOLOGY*
}

\author{
Jozef Huran ${ }^{1 *}$, Ladislav Hrubčín1,2, Pavel Boháček¹, Sergey B. Borzakov², \\ Vladimir A. Skuratov², Alexander P. Kobzev², Angela Kleinováa, Vlasta Sasinková4
}

${ }^{1}$ Slovak Academy of Sciences, Institute of Electrical Engineering, Bratislava, Slovakia

${ }^{2}$ Joint Institute for Nuclear Research, Dubna, Moscow Region, Russian Federation

3 Slovak Academy of Sciences, Polymer Institute, Bratislava, Slovakia

4Slovak Academy of Sciences, Institute of Chemistry, Bratislava, Slovakia

\begin{abstract}
Silicon carbide (SiC) and nitrogen-doped silicon carbide (SiC(N)) films were deposited on p-type Si(10o) substrates at various deposition conditions by means of plasma enhanced chemical vapor deposition (PECVD) technology using silane $\left(\mathrm{SiH}_{4}\right)$ methane $\left(\mathrm{CH}_{4}\right)$ and ammonium $\left(\mathrm{NH}_{3}\right)$ gas precursors. The concentration of elements in films was determined by RBS and ERD analytical method simultaneously. Chemical compositions were analyzed by FT-IR and Raman spectroscopy. The current-voltage (I-V) characteristics of structures before and after Xe ion and neutron irradiation were measured.
\end{abstract}

Key words: SiC film, PECVD, Xe ion and neutron irradiation, structural and electrical characterization.

DOI: $10.21175 / \operatorname{RadJ} .2016 .01 .03$

\section{INTRODUCTION}

Silicon carbide is a versatile material utilized in a wide variety of applications. Amorphous silicon carbide is an excellent alternative passivation layer material for silicon solar cells especially for work in hard and space environment. Higher band gap (1.8 $-2.3 \mathrm{eV}$ ) of amorphous SiC layers (compared to a$\mathrm{Si}: \mathrm{H})$ lead to a lower parasitic light absorption [1]. There are efforts to replace traditional passivating layers, such as $\mathrm{SiO}_{2}$ and $\mathrm{SiN}$, by a-SiC [2]. The aim is a more efficient production process involving lower deposition temperatures and high throughput. New dielectric materials such as hydrogenated amorphous silicon carbide (a-SiC:H) show great potential as both etch stop and hard mask layers to assist nanoelectronic patterning, and as low dielectric constant (i.e., low-k) interlayer dielectric, $\mathrm{Cu}$ diffusion barrier, and pore sealants. Electronic transport, particularly transport related to timedependent dielectric breakdown and stress induced leakage current, is of keen interest due to the relatively low breakdown strength of these films. a$\mathrm{SiC}: \mathrm{H}$ films with dielectric constants significantly less than a-SiN:H are particularly interesting [3]. Using a-SiC:H as a case study material, the authors utilized nuclear reaction analysis, Rutherford backscattering, nuclear magnetic resonance and transmission Fourier transform infrared spectroscopy measurements to determine the average coordination $(\langle\mathrm{r}\rangle)$ for these materials. The correlations of $\langle\mathrm{r}\rangle$ to Young's modulus, hardness, thermal conductivity, resistivity, refractive index, intrinsic stress, mass density and porosity show that an extremely wide range in material properties (in some cases several orders of magnitude) can be achieved through reducing $\langle\mathrm{r}\rangle$ via a controlled incorporation of terminal $\mathrm{Si}-\mathrm{H}_{\mathrm{x}}$ and $\mathrm{C}-\mathrm{H}_{\mathrm{x}}$ groups [4]. a-SiC:H thin films deposited by PECVD as protective coatings for harsh environment applications were investigated [5]. The effect of substrate temperature on the rate of remote microwave hydrogen plasma chemical vapor deposition of a-SiC: $\mathrm{H}$ thin films using dimethylsilane and trimethylsilane was reported [6]. Using resistivity, Raman scattering, and infrared transmission spectroscopy, the authors investigated the neutrons irradiation effect on the structure and properties of a-SiC:H films prepared by reactive sputtering method [7]. The aggregates of carbon interstitials in SiC were investigated and it was found that the formation of the carbon aggregates was energetically favored and all carbon clusters are electrically active [8].

In this paper, the PECVD technology was used for deposition of $\mathrm{SiC}$ and $\mathrm{SiC}(\mathrm{N})$ films using silane, methane and ammonium as reactants. Elements' concentrations in the films were investigated by RBS and ERD method. FT-IR and Raman spectroscopy were used for chemical composition analysis. The effect of Xe ion and neutron irradiation on the films

\footnotetext{
* The paper was presented at the Third International Conference on Radiation and Applications in Various Fields of Research (RAD 2015), Budva, Montenegro, 2015.

**elekhura@savba.sk
} 
electrical properties was studied by the measurement of the $I-V$ characteristics.

\section{EXPERIMENTS}

A plasma reactor with parallel plate electrodes was used for the PECVD technology for the films preparation. A P-type silicon wafer with the resistivity of 6-10 $\Omega \mathrm{cm}$ and (100) orientation was used as a substrate for the growth of SiC layers. Technological parameters for wafers were: the substrate temperature was $300^{\circ} \mathrm{C}$ and the gas mixture was $\left(\mathrm{SiH}_{4}-7 \mathrm{sccm}, \mathrm{CH}_{4}-40 \mathrm{sccm}\right)$ for wafer $\mathrm{HR} 1$ and $\left(\mathrm{SiH}_{4}-7 \mathrm{sccm}\right.$., $\left.\mathrm{CH}_{4}-40 \mathrm{sccm}, \mathrm{NH}_{3}-3 \mathrm{sccm}\right)$ for wafer $\mathrm{HR} 2$, respectively. For wafers the $\mathrm{RF}$ power was $150 \mathrm{~W}$ and the pressure was $100 \mathrm{~Pa}$. The wafer HR1 was cut into seven samples marked as HR1O, HR1XeA, HR1XeB, HR1XeC, HR1NA, HR1NB, HR1NAc and HR1NBc. The wafer HR2 was cut into seven samples marked as HR2O, HR2XeA, HR2XeB, HR2XeC, HR2NA, HR2NB, HR2NAc and HR2NBc. Concentration of elements in the films were analyzed using RBS and ERD analytical method simultaneously [9]. Chemical compositions were analyzed by infrared spectroscopy using a FTIR Nicolet 8700 spectrometer in the absorption mode and the absorption spectra of the used substrate were subtracted from the film spectra. Raman measurements of the SiC films were performed using a Thermo Fisher Scientific DXR Raman microscope with a $532 \mathrm{~nm}$ laser. The thickness and refractive index were determined by spectroscopic ellipsometry. Structures of $\mathrm{Au} / \mathrm{SiC} / \mathrm{Si} / \mathrm{Al}$ and $\mathrm{Au} / \mathrm{SiC}(\mathrm{N}) / \mathrm{Si} / \mathrm{Al}$ with films $\mathrm{HR} 1$ and $\mathrm{HR} 2$ of thickness about $1000 \mathrm{~nm}$ were prepared for electrical characterization. Circular electrodes of $\mathrm{Au}$ contacts with the diameter of $1.2 \mathrm{~mm}$ were formed using metal masks on the side with $\mathrm{SiC}$ film on each sample. The other side of the samples was fully covered with $\mathrm{Al}$ ohmic contact. Irradiation of structures (marked HR1Xe, HR2Xe +A,B,C) with Xe ions to total fluencies $\mathrm{A}\left(1 \times 10^{10} \mathrm{~cm}^{-2}\right), \mathrm{B}\left(1 \times 10^{11} \mathrm{~cm}^{-2}\right)$ and $\mathrm{C}\left(1{\mathrm{X} 1 \mathrm{O}^{12}}^{\mathrm{cm}} \mathrm{cm}^{-2}\right)$ was performed at room temperature in the IC10o accelerator at JINR, Dubna and irradiation of structures (marked HR1N, $\mathrm{HR} 2 \mathrm{~N}+\mathrm{A}, \mathrm{B}, \mathrm{Ac}, \mathrm{Bc})$ with neutrons to total fluencies $\mathrm{A}\left(3.3 \times 10^{13} \mathrm{~cm}^{-2}\right), \mathrm{B}\left(1.5 \times 10^{14} \mathrm{~cm}^{-2}\right)$ was performed at room temperature in the IREN facility at JINR, Dubna. The electrical properties of the structures were determined by the I-V measurement at $295 \mathrm{~K}$. An electrically shielded probe station was employed for the measurements of $I-V$ characteristics of the samples using a computer controlled HP 4140B pA meter/DC voltage source.

\section{RESUltS AND DISCUSSION}

The measured and simulated RBS and ERD spectra for HR1 and HR2 samples are shown in Fig.1. The thickness of films for RBS and ERD analysis was about $300 \mathrm{~nm}$. In Fig. 1(a), the RBS spectra are shown with the leading edge at $\sim 620 \mathrm{ch}$ corresponding to the $\mathrm{Si}$ and the leading edges around $560 \mathrm{ch}$ corresponding to the $\mathrm{SiC} / \mathrm{Si}$ interface. The feature corresponding to $\mathrm{C}$ and $\mathrm{N}$ are observed on the profile of the bulk Si at around 320 and 370 ch, respectively. In Fig. 1(b), ERD spectra, appeared one intensity corresponding to hydrogen with the leading edge at approximately $\sim 510 \mathrm{ch}$. RBS and ERD analyses indicated that the films contained silicon, carbon, hydrogen, nitrogen and a small amount of oxygen. Concentrations of species were for the HR1 sample (silicon-33 at.\%, carbon-32 at.\%, hydrogen-30 at.\%, nitrogen-1 at.\%, oxygen-4 at.\%) and for HR2 sample (32,29,28,8,3), respectively. We proposed that the small amount of oxygen in the films came from the walls of the reaction chamber as residual oxygen and from precursors. The thickness and refractive index were for the HR1 sample $(310 \mathrm{~nm}$,
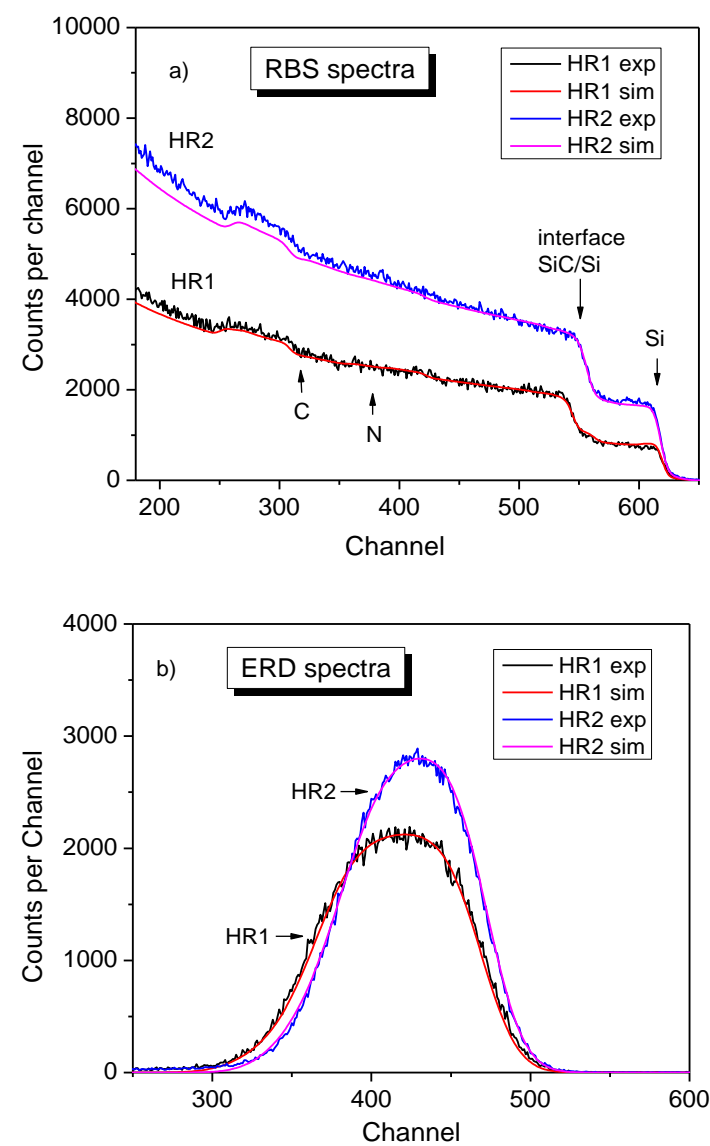

Figure 1. RBS a) and ERD b) spectra for HR1 and HR2 samples.

2.51) and for the HR2 sample (300 nm, 2.21). Figure 3 shows the FTIR spectra for HR1 and HR2 films. From the FTIR spectra we could determine the following vibration frequencies: the band at 2800 to $3000 \mathrm{~cm}^{-1}$ is attributed to stretching vibration of the $\mathrm{CH}_{\mathrm{n}}$ group in both the $\mathrm{sp}^{2}\left(2880 \mathrm{~cm}^{-1}\right)$ and sp3 (2920 
$\mathrm{cm}^{-1}$ ) configurations. The band at $2100 \mathrm{~cm}^{-1}$ appears due to $\mathrm{SiH}_{\mathrm{m}}$ stretching vibrations [10]. The band at $780 \mathrm{~cm}^{-1}$ can be assigned to $\mathrm{Si}-\mathrm{C}$ stretching vibration. The signals occur between 930 and 1200 $\mathrm{cm}^{-1}$ which are superposition of several $\mathrm{C}-\mathrm{H}$, Si-O and $\mathrm{Si}-\mathrm{N}$ vibrations

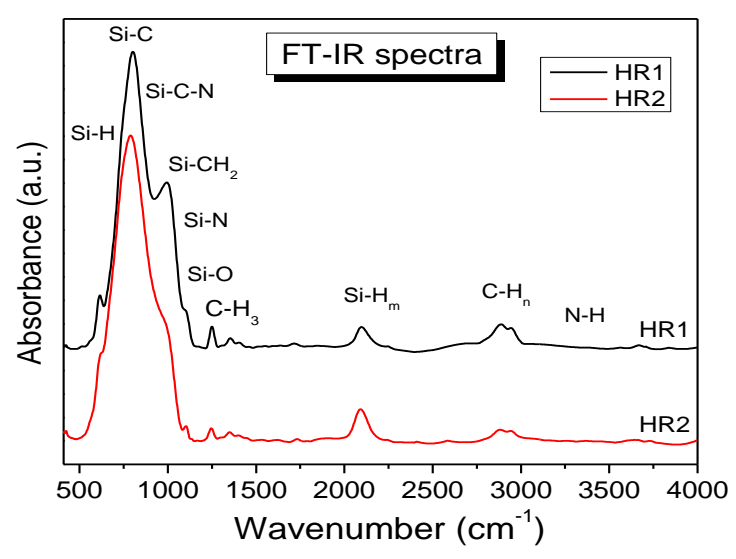

Figure 2. FT-IR spectra for HR1 and HR2 films.

$[11,12]$. The side shoulder peaking at around 1000 $\mathrm{cm}^{-1}$ is attributed to the wagging vibration of $\mathrm{CH}_{2}$ bonded to silicon in $\mathrm{Si}-\left(\mathrm{CH}_{2}\right)_{\mathrm{n}}-\mathrm{Si}$ groups. Furthermore, a small shoulder exists around 1100 $\mathrm{cm}^{-1}$ indicative of the existence of $\mathrm{Si}-\mathrm{O}$ bond. The absorption band around $3350 \mathrm{~cm}^{-1} \mathrm{can}$ be attributed to $\mathrm{N}-\mathrm{H}$ bonds. Figure 3 shows Raman spectra for HR1 and HR2 films on silicon substrate. An essential part of these spectra originated from the silicon substrate, especially the intensity of the lattice vibration at $520 \mathrm{~cm}^{-1}$. The Raman band between $930 \mathrm{~cm}^{-1}$ and $990 \mathrm{~cm}^{-1}$ was created by the acoustical and optical phonon modes of cubic or one of the hexagonal polytypes of SiC. The peak broadening is related to the damping of phonon modes due to the short range ordering of $\mathrm{SiC}$ crystallites and the effects of surroundings having $\mathrm{Si}$, as well as C-clusters [13]. The Raman band between $1300 \mathrm{~cm}^{-1}$ and $1700 \mathrm{~cm}^{-1}$ is observed for the all samples and is assigned to diamond like carbon (DLC) [14]. It is also observed that both spectra present relatively weaker band at $830 \mathrm{~cm}^{-1}$, which is typical for the amorphous SiC structure [11]. From the Raman spectra results we can conclude that HR1 and HR2 films were practically fully amorphous with very small content of $\mathrm{SiC}$ nanocrystalline phase.

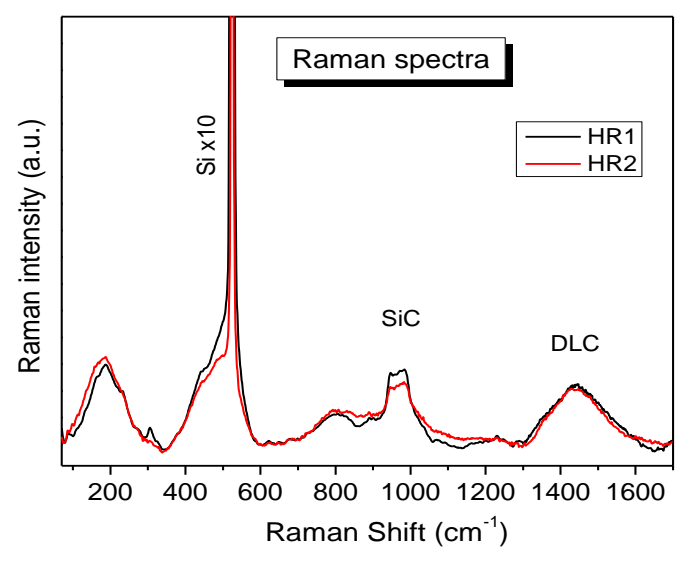

Figure 3. Raman spectroscopy results for HR1 and HR2 samples.

\subsection{MeVXe ion irradiation}

Structures with $\mathrm{HR} 1$ and HR2 films were irradiated with $167 \mathrm{MeV} \mathrm{Xe}$ ions. Damage production rate of $\mathrm{Xe}$ ions in $\mathrm{SiC}$ films calculated using SRIM2008 code equals $4 \times 10^{-17}$ $\mathrm{dpa} /$ particle $\times$ second [15]. As high energy ions penetrate into a solid, those ions can deposit kinetic energy in two processes: electronic excitation and ionization, and nuclear collision. Kinetic energy transfer between penetrating ions and target atoms takes place through collective processes of nuclear collisions in a displacement. Figure 4 shows $I-V$ characteristics of structures with HR1 films before and after irradiation with Xe ions. The measured currents were greater (up to one order) after irradiation and slightly rose up with $\mathrm{Xe}$ ion fluencies. The same effect was shown in the case of structures with $\mathrm{HR} 2$ films, figure $5 . I-V$ results showed no significance differences between $I-V$ characteristics of HR1 and HR2 structures before and after Xe ions irradiation and $I-V$ characteristic shapes are similar.

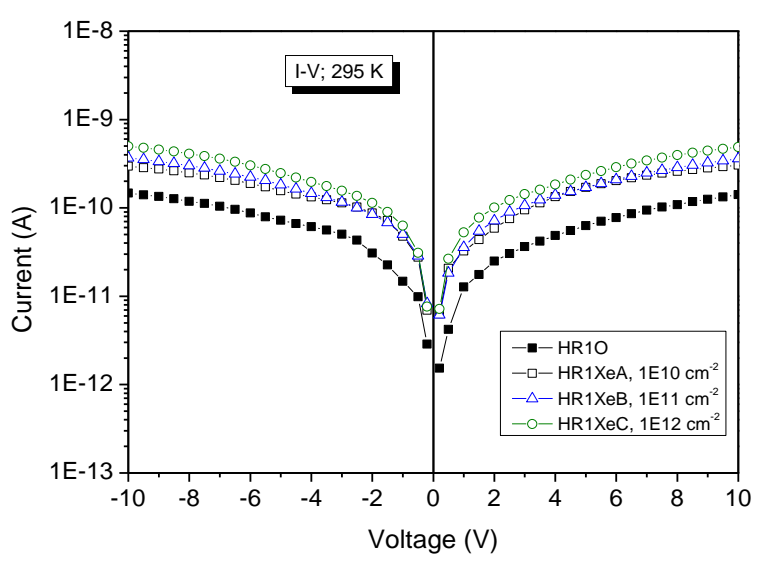

Figure 4. I-V characteristics of structures with HR1 films before and after Xe ions irradiation. 


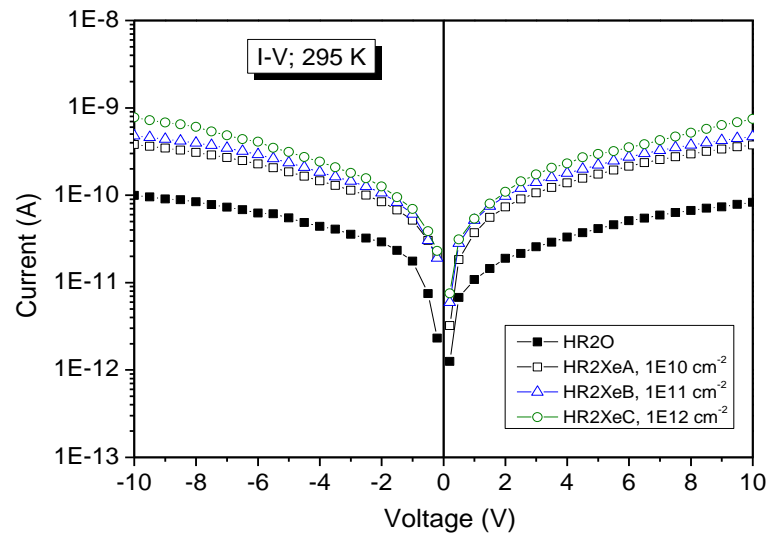

Figure 5. I-V characteristics of structures with HR2 films before and after Xe ions irradiation.

\subsection{Neutron irradiation}

Structures with HR1 and HR2 films were irradiated with neutrons. In the case of IREN facility, the flux of neutrons can be divided for several energetic regions. Main two neutron flux energetic regions are $0.4-560 \mathrm{keV}(29 \%)$ and $0.56-$ $1.4 \mathrm{MeV}$ (29\%). Cross-section (barns) at neutron incident energy $0.5 \mathrm{MeV}$ are: ${ }^{28} \mathrm{Si}-6,2 ;{ }^{12} \mathrm{C}-3,0 ;{ }^{1} \mathrm{H}-$ 5,$1 ;{ }^{14} \mathrm{~N}-3,1 ;{ }^{16} \mathrm{O}-3,2$. Cross-section (barns) at neutron incident energy $1.0 \mathrm{MeV}$ are: ${ }^{28} \mathrm{Si}-5,0 ;{ }^{12} \mathrm{C}-$ 2,$0 ;{ }^{1} \mathrm{H}-4,1 ;{ }^{14} \mathrm{~N}-1,6 ;{ }^{16} \mathrm{O}-1,2$ [16]. The value of the cross section allocated to the specific energy is for the individual elements slightly different, resulting in, the process of interaction of neutrons with a single element in the films is almost the same. Damage production rate of neutrons is about $8 \times 10^{-}$ $22 \mathrm{dpa} /$ particlexsecond. Figure 6 shows $I-V$ characteristics of structures with HR1 films before and after irradiation with neutrons a) and $I-V$ characteristics of structures with $\mathrm{HR} 1$ films in $\mathrm{Cd}$ container before and after irradiation with neutrons b). Figure 7 shows $I-V$ characteristics of structures with HR2 films before and after irradiation with neutrons a) and $I-V$ characteristics of structures with HR2 films in Cd container before and after irradiation with neutrons b). Cd container stops thermal neutrons. $I-V$ results showed no significance effect of the $\mathrm{Cd}$ container on the electrical characteristics.
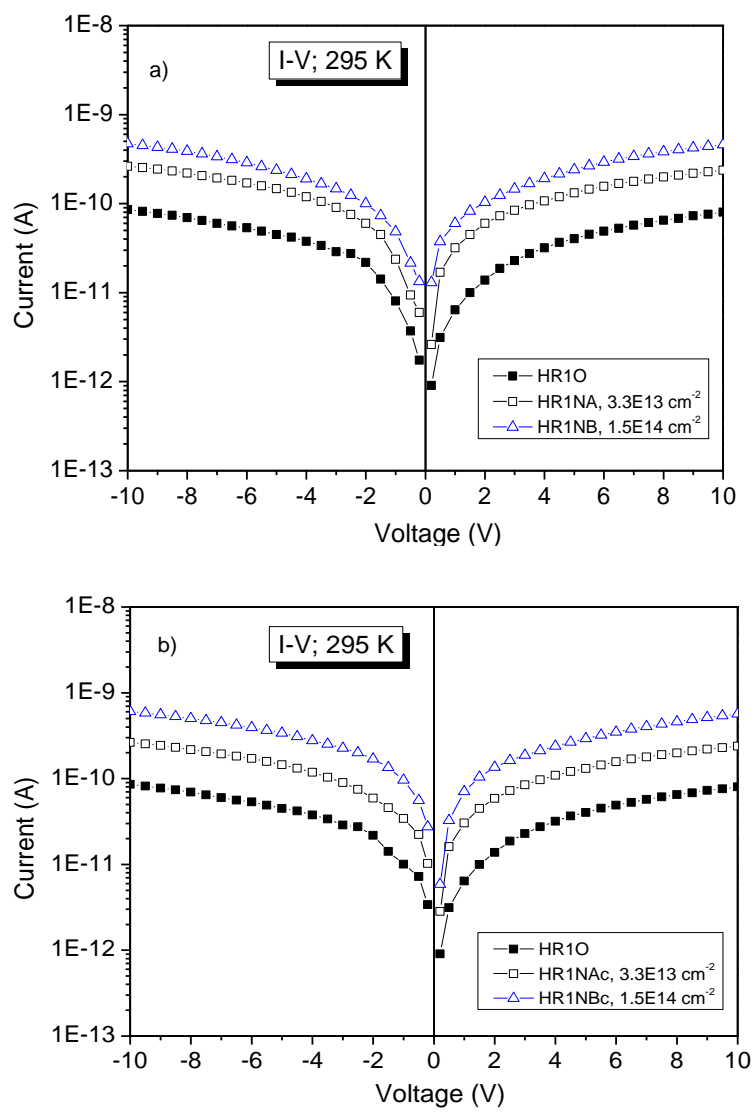

Figure 6. I-V characteristics of structures with HR1 films before and after irradiation with neutrons a), in Cd container b).

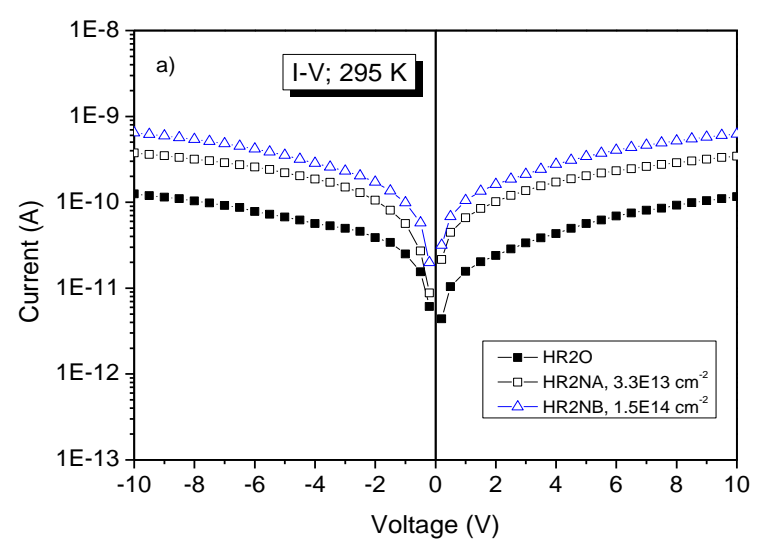




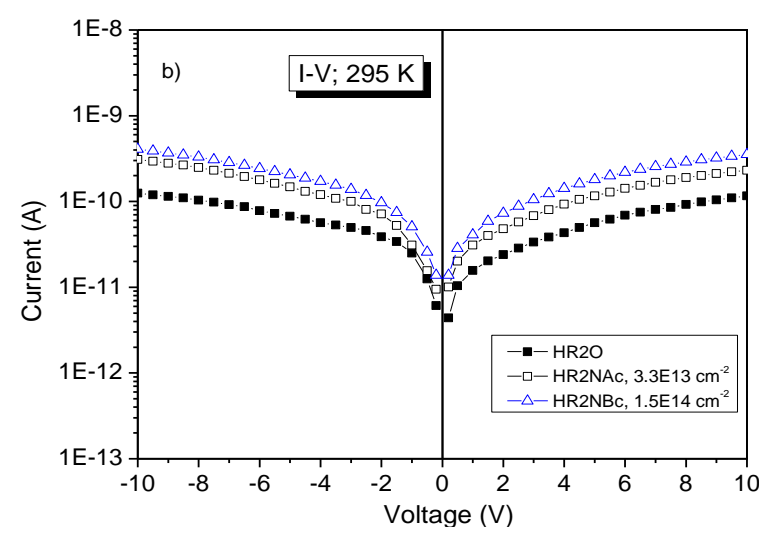

Figure 7. I-V characteristics of structures with HR2 films before and after irradiation with neutrons a), in $\mathrm{Cd}$ container b).

The measured $I-V$ characteristics of both sets of structures HR1 and HR2 are similar. $I-V$ dependencies of all investigated structures before and after irradiation with Xe ions and neutrons have almost linear behavior for both polarity of the bias voltage ranging from 0.2 to $10 \mathrm{~V}$. The structures HR1 and HR2 don't exhibit any rectification ratio. The measured current increases approximately 3 times after irradiation with Xe ions at fluence of $1 \times 10^{12} \mathrm{~cm}^{-2}$ and measured current increases 5-6 times after irradiation with neutrons at fluence of $1.5 \times 10^{14} \mathrm{~cm}^{-2}$ at bias voltage of $10 \mathrm{~V}$ in case of samples HR1. For investigated samples HR2 the measured current increases about 8 times after irradiation with $\mathrm{Xe}$ ions at highest fluence and measured current increases 3-5 times after irradiation with neutrons at fluence of $1.5 \times 10^{14} \mathrm{~cm}^{-2}$ at bias voltage of $10 \mathrm{~V}$. Observable influence of the thermal neutron shielding at the irradiation of structures, using a Cd container is relatively small. The higher measured current after irradiation with Xe ions and neutrons might be due to breaking of the most slightly bonded $\mathrm{Si}-\mathrm{H}, \mathrm{C}-\mathrm{H}$ and $\mathrm{N}-\mathrm{H}$ bonds therefore creating more dangling bonds and so increasing number of defect centers in the films responsible for the higher conductivity [17]. It should be noted that difference in damage production rate for $167 \mathrm{MeV}$ Xe ions and neutrons in $\mathrm{SiC}$ films is about $5 \times 10^{4}$.

\section{CONCLUSION}

We have investigated the structural properties of $\mathrm{SiC}$ and $\mathrm{SiC}(\mathrm{N})$ films prepared by plasma enhanced chemical vapour deposition. The RBS and ERD results showed main concentrations of $\mathrm{Si}, \mathrm{C}$ and $\mathrm{H}$ in the SiC films. The concentration of hydrogen was about 30 at.\% and $\mathrm{SiC}(\mathrm{N})$ film contained 8 at.\% nitrogen. The FT-IR results of the SiC films showed the presence of the $\mathrm{Si}-\mathrm{C}, \mathrm{Si}-\mathrm{H}, \mathrm{C}-\mathrm{H}, \mathrm{Si}-\mathrm{N}, \mathrm{N}-\mathrm{H}$ and $\mathrm{Si}-\mathrm{O}$ bonds. Raman spectroscopy results showed interesting band between $930 \mathrm{~cm}^{-1}$ and $990 \mathrm{~cm}^{-1}$ which was created by the acoustical and optical phonon modes of cubic or one of the hexagonal polytypes of $\mathrm{SiC}$ and band between $1300 \mathrm{~cm}^{-1}$ and $1700 \mathrm{~cm}^{-1}$ which was assigned to sp2 graphitic clusters that commonly exist in diamond like carbon films. Structures with metal contacts were irradiated with $\mathrm{Xe}$ ions and neutrons. Electrical results showed no rectifying effect in the measured $I-V$ characteristics before and after irradiation with Xe ions and neutrons. $I-V$ dependencies of all investigated structures before and after irradiation with $\mathrm{Xe}$ ions and neutrons have almost linear behavior for both polarity of the bias voltage ranging from 0.2 to $10 \mathrm{~V}$. The measured currents of structures after irradiation are greater than the current before irradiation and rose up with a higher fluence of Xe ions and neutron irradiation for both polarities of the bias voltage. Observable influence of the thermal neutron shielding using a Cd container is relatively small. The higher measured current after irradiation might be caused by breaking $\mathrm{Si}-\mathrm{H}$, $\mathrm{C}-\mathrm{H}$ and $\mathrm{N}-\mathrm{H}$ bonds and so increasing the number of defect centers in the films responsible for the higher conductivity of films.

Acknowledgements This research has been supported by the Slovak Research and Development Agency under the contracts APVV0443-12 and by the Scientific Grant Agency of the Ministry of Education of the Slovakia and Slovak Academy of Sciences, No. 2/oo62/13; 2/o175/13; 2/o173/13.

\section{REFERENCES}

1. D. Pysch et al., "Potentials and Development of Amorphous Silicon Carbide Heterojunction Solar Cells," Proc. 34th IEEE Photov. Spec. Conf., Philadelphia (PA), USA, 2009, pp. 794-799.

2. S. Janz, S. Reber and W. Glunz, "Amorphous SiC: Applications for Silicon Solar Cells," Proc. 21st EUPVSEC, Dresden, Germany, 2006, pp. 660-663.

3. T.A. Pomorski, B.C. Bittel, C.J. Cochrane, P.M. Lenahan, J. Bielefeld and S.W. King, "Defects and Electronic Transport in Hydrogenated Amorphous SiC Films of Interest for Low Dielectric Constant Back End of the Line Dielectric Systems," J. Appl. Phys., vol. 114, p. 074501, 2013.

4. S.W. King et al., "Influence of Network Bond Percolation on the Thermal, Mechanical, Electrical and Optical Properties of High and Low-k a-SiC: $\mathrm{H}$ Thin Films," J. Non-Crystal. Solids, vol. 379, pp. 6779, Nov. 2013.

5. W. Daves, A. Krauss, N. Behnel, V. Häublein, A. Bauer and L. Frey, "Amorphous Silicon Carbide Thin Films (a-SiC:H) Deposited by Plasma-Enhanced Chemical Vapor Deposition as Protective Coatings for Harsh Environ-ment Applications," Thin Solid Films, vol. 519, pp. 5892-5898, Jul. 2011.

6. A.M. Wrobel, A. Walkiewicz-Pietrzykowska and P. Uznanski, "Remote Hydrogen Microwave Plasma Chemical Vapor Deposition from Methylsilane 
Precur-sors. 1. Growth Mechanism and Chemical Structure of Deposited a-SiC:H Films," Thin Solid Films, vol. 564, pp. 222-231, Aug. 2014.

7. 刘贵昂, 谢二庆, 王天民, “a-SiC:

H薄膜的中子辐照研究, ” Qiangjiguang Yu Lizishu, 第 15 卷第 3 期 2003 年 3 月. (G.A. Liu, E.Q. Xie and T.M. Wang, "Irradiation Effect of Neutrons on a-SiC:H Films," High Pow. Las. Part. Beams, vol. 15, no.3, pp. 271-274, Mar. 2003.)

8. A. Gali, P. Deák, P. Ordejón, N. T. Son, E. Janzén and W. J. Choyke, "Aggregation of Carbon Interstitials in Silicon Carbide: A Theoretical Study," Phys. Rev., vol. B 68, pp. 125201 (11), Sep. 2003.

9. A.P. Kobzev, J. Huran, D. Maczka and M. Turek, "Investi-gation of Light Element Contents in Subsurface Layers of Silicon," Vacuum, vol. 83, supl.1, pp. S124-S126, May, 2009.

10. S.F. Yoon and J. Ahn, "Electron Cyclotron Resonance Deposition of Wide Bandgap a-SiC:HFilms Using Acetylene Under High Hydrogen Dilution," J. Mater. Sci. Technol., vol. 13, no. 3, pp. 189-193, 1997.

11. M.A. Fraga, M. Massi, I.C. Oliviera, H.S. Maciel, S.G.S. Filho and R.D. Mansano, "Nitrogen Doping of SiC Thin Films Deposited by RF Magnetron Sputtering," J. Mater. Sci., vol. 19, no. 8, pp. 835840, Sep. 2008.

12. M. Künle, T. Kaltenbach, P. Löper, A. Hartel, S. Janz,
O. Eibl and K-G. Nickel, "Si-rich a-SiC: H Thin Films: Structural and Optical Transformations during Thermal Annealing," Thin Solid Films, vol. 519, no.1, pp. 151-157, Oct. 2010.

13. J.K. Seo, Y-H. Joung, Y. Park and W.S. Choi, "Substrate Temperature Effect on the SiC Passivation Layer Synthesized by an RF Magnetron Sputtering Method," Thin Solid Films, vol. 519, pp. 6654-6657, Aug. 2011.

14. T. Chen, Y. Huang. D. Yang, R. Carius and F. Finger, "Development of Microcrystalline Silicon Carbide Window Layers by Hot-Wire CVD and their Applications in Microcrystalline Silicon Thin Film Solar Cells," Thin Solid Films, vol. 519, no. 14, pp. 4523-4526, May 2011.

15. В.И. Авраменко, Ю.В. Конобеев и А.М. Строкова "Нейтронные сечения для расчёта повреждающей дозы в реакторных материалах," Атомная енергия, т. 56. но. 3, с. $139-141$, 1984 . (V.I. Avramenko, Yu.V. Konobeev and A.M. Strokova, "Neutron Cross-sections for Calculation of the Reactor Materials Damage Dose," (Atomic Energy), vol. 56, no. 3, pp. 139-141, 1984.

16. National Nuclear Data Center, Upton (NY), USA. Retrieved from: http://www.nndc.bnl.gov/

17. M. Vetter et al., "Electronic Properties of Intrinsic and Doped Amorphous Silicon Carbide Films," Thin Solid Films, vol. 511-512, pp. 290-294, Jul. 2006. 